\title{
Parental Experiences Before and After Dialogical Family Guidance in Families With a Child With Neurodevelopmental Disorders
}

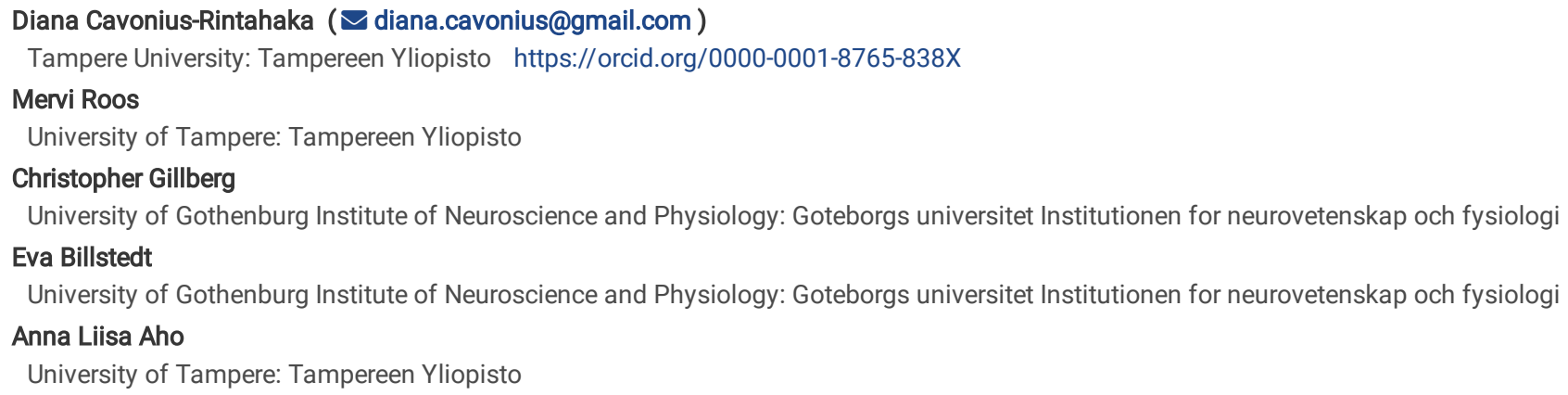




\section{Abstract}

Background: Previous studies have highlighted the need to offer targeted effective interventions to strengthen the wellbeing of all family members in families with children with neurodevelopmental disorders (NDD). Interventions for this target group requires development and research. The purpose of this study was to test a new family intervention (Dialogical Family Guidance / DFG).

Method: Fifty families of children with NDD took part in this study. Families were randomized into two groups. Families in Intervention group I were delivered DFG immediately, and families in Intervention group II were delivered DFG after three months. Family functionality, health and support (FAFHES) and DFG intervention parent questionnaires were used to collect data at baseline, and after three and six months. Thirty-four families completed the whole protocol.

Results: Intervention group I experienced better family health and family support after DFG compared to baseline, and the experience of increased support remained at the three month follow-up.

Intervention group II also experienced better family support after three months compared to baseline, although they were still waiting for DFG to initiate. Intervention group II continued to increase the experience of support throughout DFG. The positive changes were statistically significant concerning the experience of social support.

Managing as a parent in daily life and the relationship between parents were associated with family functionality and family health. Most parents ' reported that DFG had helped them manage better with their child with NDD, and that they would recommend DFG to other families.

Conclusion: The study findings suggest that the DFG intervention may strengthen parent experiences of family support. Managing as a parent in daily life and the relationship between parents was associated with family functionality and family health. DFG parent questionnaire inform that practical guidance, psychoeducation, dialogue with the staff and positive feedback for own parenthood are strengthening factors. Delivering DFG as a family intervention implemented by healthcare staff can be recommended as an additional type of support for families with a child with NDD.

Trial registration: ClinicalTrials.gov NCT04892992 (retrospective registered)

\section{Background}

Neurodevelopmental disorders (NDD) are a group of disorders with onset in the developmental period of childhood. NDD is a general term to describe neurological and psychiatric disorders such as learning and language disorders, intellectual disabilities, motor coordination disorders, autism spectrum disorders (ASD), attention-/deficit/hyperactivity disorder (ADHD), tic disorders, and oppositional defiant disorder (ODD). NDDs are characterized by high rates of impairment or comorbidities between various disorders within this diagnostic grouping.[1]. Common comorbidities are eg, oppositional defiant disorder (ODD), conduct disorder, generalized anxiety disorder and reading disability [2]. At least one comorbid disorder appeared alongside ADHD in up to $90 \%$ of subjects in a population-based twin study of children with ADHD [2]. Symptoms and the profile of NDD development may also change during childhood, and these multiple NDD symptoms can be presented in a concept of ESSENCE (Early Symptomatic Syndromes Eliciting Neurodevelopmental Clinical Examinations) [3]. Having a child with NDD often means that other members in the family (parent or siblings) are also likely to have NDD symptoms due to strong genetic influences [4]. According to findings from twin, family and adoption studies, the heritability of ADHD is estimated to be at 70-80\% [5-7]. According to Chen, Brikell, Lichtenstein et al [8], ADHD manifests eg in parents or siblings of children with an ADHD diagnosis 2-8 times more frequently than seen in the population in general. Genetics also affect the etiology of ASD and the heritability is estimated to be between 64-91\% [9-11]. It is also known that both disorders co-occur with a frequency of $20-50 \%$ in children with ADHD meeting criteria for ASD, and $30-80 \%$ of ASD children meeting criteria for ADHD [12]. Interventions to improve health and functioning for both parents and the children are needed, considering the fact, that parents of special needs children demonstrate fatigue and exhaustion, and emotional problems ranging from frustration to hopelessness [13]. Yet only a few studies investigate the effects on family functioning and relationship factors inside the family [14]. We also know that parents of children with NDD such as ASD, experience more stress than parents of typically developing children [15-17]. High levels of parenting stress may have negative effects on the entire family system, and the individual's life quality. According to Hartley et al [18], divorce rates remain higher in parents of children with autism, compared to parents of normally developed children. Studies reveal that there is a relationship between family functioning, quality of life and characteristics common to children with a range of NDD disabilities and parental stress levels $[15,19]$. It is also known that parents with ADHD themselves have a weaker sense of coherence and poorer family functioning than parents without ADHD, and support from health services is strongly associated with a positive effect on family functioning.[20] Arnold, 0 'Leary and Edwards [21] report that parent involvement is predicted more ineffective when the parent have ADHD. Adults with ADHD is known to have more depression, anxiety, greater childhood dissatisfaction, a more external locus of control and lower self-esteem [22]. Less organized family environment can exacerbate impulsive and hyperactive child behavior to more serious level, instead of facilitating self-regulation skills to the child. Shared genetic vulnerabilities combined with child difficulties and stress in families is family environmental risk [16]. Moen, Hedelin \& Hall-Lord [20] reported in their study parents with ADHD having a weaker sense of coherence and poorer family functioning than parents without ADHD. ADHD in parents appears to confer specific impairments in parental functioning in families of children with ADHD [16]. According to Craig et al [15], parents can gain empowerment and better well-being through increased appropriate personal resources in the parental role and knowledge about behavioral responses to stress. Also other studies [23-25] report that, caregiver training and interventions have a general impact on family functionality and the relationships within the families. This suggest that parent and family involvement and the inclusion of family members in interventions would probably result in a greater effectivity and impact of treatments for the entire family $[26,27]$. Dialogical Family Guidance (DFG) was developed as a family intervention with the purpose to help all of the family members receive psychoeducation and increase understanding of NDD/ESSENCE.[28] Results from a range of earlier studies have been taken into account during the development and implementation process of the DFG family intervention [14, 23, 24, 28-37]. Because DFG is a new family intervention, there is limited knowledge and only subjective opinions about aspects of its effects from clinical practice. It is therefore important to study the effects of DFG, with regard to Loading [MathJax]/jax/output/CommonHTML/jax.js sing a randomized controlled intervention design. It is of particular interest to discover whether DFG is 
appropriately designed to meet the needs of families with a child with NDD. The aim of present research is to study possible effects on parent experience of DFG in affected families, using the two questionnaires; Family functionality, Health and Social support (FAFHES) [38, 39] and DFG questionnaire designed for this study.

\section{Method}

\section{Participants}

Study participants were families with children referred to a neuropsychiatric unit at a University clinic that provides multidisciplinary assessments and rehabilitation plans by team of child neurologist, child psychiatrists, (neuro-)psychologists, nurses, occupational therapists, language therapists, and social workers. Interventions and rehabilitation of the child can be carried out within the hospital or at a clinic within the primary health care system.

All parents included in this study had a child with at least one diagnosis under the NDD umbrella (eg ADHD, ASD, tics, language disorders), aged between 4-16 years old. Most children had ADHD or ASD as the main diagnosis, but also co-morbid conditions appeared. An additional criterion for inclusion in the study was that parents had adequate Finnish language skills and that they were the biological parents or stepparents of the child.

From the very beginning, the study design plan was to include fifty families to this study. Seventy-nine families met the inclusion criteria during data collection period (2016-2018) and when fifty families gave their consent to the study, the recruitment of families ended. Reasons for refusal $(n=29)$ were problems with time-schedules ( $n=17)$, having long way to the clinic $(n=3)$, parents` feeling not needing/not interested in DFG ( $n=5)$, other policlinic visits coming up ( $n=3)$ and language issues $(n=1)$. From these fifty families $(n=50)$, sixty parents participated in the study at baseline. Thirty-four $(n=34)$ families completed all phases of the study.

\section{Study Design and data collection}

All parents who attended the unit with their child (aged between 4-16 years old) were asked to take part in this study. A particular research assistant nurse at the unit gave oral and written information to parents about the study, including information about the DFG family intervention. All families who gave their written consent to participate were delivered the DFG family intervention. These families were randomized into two groups creating intervention group I and intervention group II. Every second family who gave their consent to the study was put by the research assistant nurse into intervention group I and every second family to intervention group II. Families in intervention group I were delivered DFG with an immediate starting point (baseline), and families in intervention group II were delivered DFG with a starting point three months after the baseline (Figure 1). Parents could not choose themselves in what group they were placed in and parent questionnaires completed at baseline did not have an impact in what group the families were placed in. Both groups simultaneously received treatment as usual at the neuropsychiatric unit, which. Treatment as usual in the current hospital focused mainly on the child sassessment $\rightarrow$ clar if ythediagnosis and $\rightarrow$ plantreatment and habilitationofthe $\chi$ ld. Systematicfamily $\int$ erventionsare $\neg$ partofthe $\chi$ lds routine intervention. The researcher was not involved with the families and did not deliver DFG to study participants. The researcher was educating the staff into DFG and functioning as supervisor during the study.

\section{Procedures and intervention}

DFG is a family intervention tailored specifically for families with a child with NDD. The development process is based on clinical experience, practice, theorybased research and a pilot study [28]. The aim with DFG is to help all family members receive knowledge and gain an understanding of NDD/ESSENCE and providing a reflective space for family members to discuss their worries, thoughts and feelings. The DFG structure is based on three guidance areas; psychoeducation (didactic element), practical guidance for daily life (skill training), and emotional guidance. Emotional guidance include their personal stories and unique experiences. Alongside the psychoeducation, the DFG-therapist is interested in identifying the challenges and needs of all family members.

The DFG-therapist and family members collaborate and seek together for effective parent strategies, skills to strengthen family members relationships and havedialogue $\rightarrow$ meettheir $\in \div$ algoals. Dur $\in$ gthesessions, DFG - theranstsga $\in$ know $\leq d \geq$ aboutegthefamilysystem, i relationship, family crises, and siblings' reactions within the family. NDD can have different impacts on family members, and open dialogue can invite family members to a mutual learning process about the family dynamic and communication inside the family. It is important to teach parents effecting parenting strategies, but many parents simply need the space to discuss worries, thoughts and feelings [40,41].

The DFG collaborative working process for family members lasts over six meetings (90 minutes per session) within a 3-month period. The first intervention session begins with dialogue between DFG-therapist and parents followed by an initial plan. A DFG-manual is provided to give structure to the DFG intervention process and a session checklist is used to monitor content adherence. The manual includes suggested themes for each session (eg child`s development and demands in daily life, family resources and network, communication in the family, relation between siblings). Health care professionals (mainly nurses) participate in three day long educational process before being allowed to deliver DFG to families.

\section{Questionnaires}

The FAFHES questionnaire [42] was originally developed for patients with cardiac illness and their family members to study their experiences regarding family functionality, health and the social support received from personnel at hospital. FAFHES has been used in different context in studies thereafter [43, 44].

The FAFHES questionnaire contains three sections; family functionality (19 items), family health (23 items), and family support provided by professionals ( 21 items). All the items are measured on a Likert scale ranging from 1-6 (I disagree totally, I disagree, I disagree somewhat, I agree somewhat, I agree, I agree 
totally). Family functionality, family health and family support were seen as poor if the median was $1.00-2.7$, moderate if it was $2.8-4.5$, and good if it was 4.6 $6.0[45]$.

The DFG-questionnaire was developed for this study to obtain information and parents` experiences about the DFG family intervention. The questionnaire include 14 items. Questions concerning the amount and time consumed on DFG sessions were included as "Is six sessions the right number of sessions?" (Yes/No) and "How many sessions are suitable for DFG, according to you?" (1=1, 2=2.....6=6). Questions about the content and recommendation of DFG sessions were for example: "Did you get practical tips for daily life?" (1= yes absolutely....5=not at all) and "Would you recommend DFG to other parents?" ( $1=y e s$ absolutely....4=no). The following semi-structured open-ended question was included in the DFG-questionnaire: Could you describe your experiences, comments or/and ideas about how to improve DFG? Parents filled the questionnaire after completing the DFG process (six meetings).

Demographic data was collected at the baseline stage of the study. The demographic data for parents were obtained in the first section in the FAFHES parent questionnaire including; gender, age, marital status, quality of relationship between parents (extremely good, good, average, poor, extremely poor), basic education, professional education, number of children, other members of the family having NDD or related diagnoses, parents

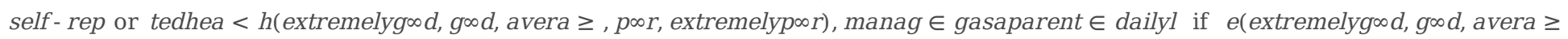
$s$ daytime activity, diagnose on the referral, parentsfirstconcerna or $d \in g \rightarrow$ the $\chi$ lds neuropsychiatric problems, the effect of the child

$s N D D o n h i \frac{s}{h}$ erdailyl if $e$, and the $\chi$ lds earlier visits to the clinic. In addition to parent questionnaires, official medical reports were used to include the diagnosis of the children to baseline demographics. The diagnoses of the children were defined by medical doctors and set before (diagnosis already on the referral) or during the study on the neuropsychiatric clinic. Potential additional diagnosis received after the study period was not included.

All families participated in six sessions, but the number of family members (fathers, mothers, the child with NDD and siblings) participating varied during DFGprocesses depending on familiesunique $\neq e d s$ and parents wishes. Both parents from the same family had the opportunity to complete their own FAFHES and DFG-questionnaires. The parent / parents` completed the questionnaires when visiting the unit.

\section{Data analysis}

SPSS statistical program was used and data were analyzed using descriptive statistics. The total scores for three FAFHES sum variables were calculated by summing the score for all of items in the variable and dividing the sum by the number of items. The internal consistency of the scale was evaluated using Cronbach's alpha coefficients. The internal consistency of the scale based on Cronbach`s alpha values were .78-.98. The Kolmogorov-Smirnov test was applied to verify that the FAFHES sum variables were normally distributed.

To compare the data between the Intervention group I and Intervention group II, the background variables were examined using the Chi square for categorial variables and the Mann Whitney U-test or Kruskal Wallis H-test for continuous variables. The paired t-test was applied to check whether there were significant differences between the three measurement times for the FAFHES sum variables. The level of significance ( $p$ ) was set as $\leq 0.05$. Statistical analysis was carried out using IBM SPSS Statistics for Windows, version 26.

The additional semi-structured open-ended question from the DFG-questionnaire was analyzed using content analysis [46]. The content analysis followed a procedure using inductive content analysis, and therefore the variables were not identified in advance. The qualitative analysis began by reading parents' written responses and frequent reference to questions addressed in this study were highlighted. This was followed by an identification of similar sentences. Similar references were classified as a "subcategory" (grouping and combining similar or related answers). These subcategories were named relating to the actual content, and present parents` opinions and hopes formulated to the upcoming themes. The last step in the content analysis was to create "main categories" based on "subcategories" by analysing similarities and differences relating to the content. The results are presented as five main categories.

\section{Results}

\section{Demographic data of participants}

Group I and group II consisted at baseline of a total of 50 families and from 10 families both parents participated (60 parents at baseline). Of these, 32 parents were in Intervention group I and 28 parents in Intervention group II. There were no statistically significant differences in background variables between the intervention groups, and the characteristics of the children were also quite similar in both groups (Table 1). However, there were differences concerning family health at baseline being better in Intervention group II than in Intervention group. The mean age of the parents at baseline was 38 years (SD 5), and the mean age of parents in Intervention group I was 37 (SD 5) and Intervention group II was 39 (SD 6). In both groups, the mean number of children was 2 (SD 1 , minimum 1 and maximum 6). 


\begin{tabular}{|c|c|c|c|c|c|c|c|}
\hline \multirow[b]{2}{*}{ Background variables } & \multicolumn{2}{|c|}{ All participants } & \multicolumn{2}{|c|}{$\begin{array}{l}\text { Intervention } \\
\text { group I }\end{array}$} & \multicolumn{2}{|c|}{$\begin{array}{l}\text { Intervention } \\
\text { group II }\end{array}$} & \multirow[b]{2}{*}{ p-value } \\
\hline & $\mathbf{n}$ & $\%$ & $\mathbf{n}$ & $\%$ & $\mathrm{n}$ & $\%$ & \\
\hline Gender & & & & & & & 0.464 \\
\hline Father & 20 & 33.7 & 12 & 37.5 & 8 & 28.6 & \\
\hline Mother & 40 & 66.7 & 20 & 62.5 & 20 & 71.4 & \\
\hline Age (years) & & & & & & & 0.427 \\
\hline$<38$ & 29 & 48.3 & 17 & 53.1 & 12 & 42.9 & \\
\hline$\geq 38$ & 31 & 51.7 & 15 & 46.9 & 16 & 57.1 & \\
\hline Marital status & & & & & & & 0.550 \\
\hline Married/ cohabiting & 45 & 75.0 & 23 & 71.9 & 22 & 78.6 & \\
\hline Do not live together & 15 & 25.0 & 9 & 28.1 & 6 & 21.4 & \\
\hline Quality of the relationship between parents & & & & & & & 0.329 \\
\hline Excellent/ good & 39 & 65.0 & 19 & 59.4 & 20 & 71.4 & \\
\hline Moderate/ poor/ very poor & 21 & 35.0 & 13 & 40.6 & 8 & 28.6 & \\
\hline Basic education & & & & & & & 0.366 \\
\hline Comprehensive school & 18 & 30.0 & 8 & 25.0 & 10 & 35.7 & \\
\hline Matriculation examination & 42 & 70.0 & 24 & 75.0 & 18 & 64.3 & \\
\hline Professional education & & & & & & & 0.330 \\
\hline University degree & 34 & 56.7 & 20 & 62.5 & 14 & 50.0 & \\
\hline College level degree or lower & 26 & 43.3 & 12 & 37.5 & 14 & 50.0 & \\
\hline Number of children & & & & & & & 0.740 \\
\hline 1 child & 11 & 18.3 & 7 & 21.9 & 4 & 14.3 & \\
\hline 2 children & 28 & 46.7 & 14 & 43.8 & 14 & 50.0 & \\
\hline$\geq 3$ children & 21 & 35.0 & 11 & 34.4 & 10 & 35.7 & \\
\hline Other members of the family with neurodevelopmental disorders or diagnoses & & & & & & & 0.271 \\
\hline Yes & 16 & 29.1 & 10 & 35.7 & 6 & 22.2 & \\
\hline No & 39 & 70.9 & 18 & 64.3 & 21 & 77.8 & \\
\hline Parents' self-reported health & & & & & & & 0.775 \\
\hline Very good / good & 46 & 76.7 & 25 & 78.1 & 21 & 75.0 & \\
\hline Moderate/ poor/ very poor & 14 & 23.3 & 7 & 21.9 & 7 & 25.0 & \\
\hline Managing as a parent in daily life & & & & & & & 0.265 \\
\hline Extremely well/ quite well & 34 & 56.7 & 16 & 50.0 & 18 & 64.3 & \\
\hline Moderate/ rather/ Extremely poor & 26 & 43.3 & 16 & 50.0 & 10 & 35.7 & \\
\hline Having long-term illness or neuropsychiatric disorder & & & & & & & 0.149 \\
\hline Yes & 16 & 26.7 & 11 & 34.4 & 5 & 17.9 & \\
\hline No & 44 & 73.3 & 21 & 65.6 & 23 & 82.1 & \\
\hline
\end{tabular}

The characteristics of the children in Intervention groups I and II were quite similar in both groups (Table 2). The median age of all children was 6 ( $Q_{1} 5$; $Q_{3} 8$ ) Intervention group I was $6\left(Q_{1} 5, Q_{3} 7\right)$ and intervention group II was $7\left(Q_{1} 5, Q_{3} 8\right)$. The median age of the child when parents first became concerned regarding the neuropsychiatric problems, was $3\left(Q_{1} 2, Q_{3} 4\right)$ in both Intervention groups. The mean number of child`s visits to the hospital or clinic before $D F G$ were 5 (SD 3). 


\begin{tabular}{|c|c|c|c|c|c|c|c|}
\hline \multirow[b]{2}{*}{ Background variables } & \multicolumn{2}{|c|}{$\begin{array}{l}\text { All } \\
\text { children }\end{array}$} & \multicolumn{2}{|c|}{$\begin{array}{l}\text { Intervention } \\
\text { group I }\end{array}$} & \multicolumn{2}{|c|}{$\begin{array}{l}\text { Intervention } \\
\text { group II }\end{array}$} & \multirow[b]{2}{*}{$\mathbf{p}^{1}$} \\
\hline & $\mathbf{n}$ & $\%$ & $\mathbf{n}$ & $\%$ & $\mathbf{n}$ & $\%$ & \\
\hline Gender & & & & & & & 0.036 \\
\hline Girl & 11 & 18.3 & 9 & 28.1 & 2 & 7.1 & \\
\hline Boy & 49 & 81.7 & 23 & 71.9 & 26 & 92.9 & \\
\hline Age (years) & & & & & & & 0.466 \\
\hline$<7$ & 33 & 55.0 & 19 & 59.4 & 14 & 50.0 & \\
\hline$\geq 7$ & 27 & 45.0 & 13 & 40.6 & 14 & 50.0 & \\
\hline Child's daytime activity & & & & & & & 0.078 \\
\hline In daycare & 43 & 71.7 & 26 & 81.3 & 17 & 60.7 & \\
\hline At school & 17 & 28.3 & 6 & 18.8 & 11 & 39.3 & \\
\hline Diagnose of the child & & & & & & & - \\
\hline Attention-deficit/hyperactivity disorder & 15 & 25.0 & 9 & 28.1 & 6 & 21.4 & \\
\hline $\begin{array}{l}\text { Autism spectrum disorder (e.g. Aspergers } \\
\text { syndrome) }\end{array}$ & 15 & 25.0 & 7 & 21.9 & 8 & 28.6 & \\
\hline Delayed milestone & 11 & 18.3 & 9 & 28.1 & 2 & 7.1 & \\
\hline Speech and language disorders & 8 & 13.5 & 4 & 12.5 & 4 & 14.3 & \\
\hline Specific learning disorder & 4 & 6.7 & - & - & 4 & 14.3 & \\
\hline Other (motoric or psychiatric problems, unclear) & 7 & 11.7 & 3 & 9.4 & 4 & 14.3 & \\
\hline First concern towards the child's neuropsychiatric problems & & & & & & & 0.366 \\
\hline 1-3 years & 42 & 17.0 & 24 & 75.0 & 18 & 64.3 & \\
\hline$>3$ & 18 & 30.0 & 8 & 25.0 & 10 & 37.7 & \\
\hline How the child's NDD problems affect his/her daily life & & & & & & & - \\
\hline No symptom/hardly any symptoms & 3 & 5.0 & 1 & 3.1 & 2 & 7.1 & \\
\hline Symptoms occasionally & 7 & 11.7 & 2 & 6.3 & 5 & 17.9 & \\
\hline Symptoms often & 25 & 41.7 & 16 & 50.0 & 9 & 32.1 & \\
\hline Symptoms disturbing all the time & 25 & 41.7 & 13 & 40.6 & 12 & 42.9 & \\
\hline Earlier visit to the clinic/hospital & & & & & & & 0.448 \\
\hline Yes & 31 & 51.7 & 18 & 56.3 & 13 & 46.4 & \\
\hline No & 29 & 48.3 & 14 & 43.8 & 15 & 53.6 & \\
\hline${ }^{1} \mathrm{p}$-value & & & & & & & \\
\hline
\end{tabular}

\section{Parents' experience of family functionality, health and social support}

Family functionality and family health were moderate at every measure (T1, T2, T3) in Intervention group I (Table 3) and family support was good. In Intervention group II, family functionality and family support were good at every measure and family health was moderate.

In the baseline evaluation (T1), Family health was lower in Intervention group I compared to Intervention group II. In Intervention group I, the mean of Family health was 3,9 and in Intervention group II 4,2 ( $p=0,041)$.

In the three months evaluation (T2), Family support was higher in Intervention group I, compared to Intervention group II. In Intervention group I, the mean of Family support was 5,2 and in Intervention group II 4,5 ( $p=0,001)$. 


\begin{tabular}{|c|c|c|c|c|c|c|c|c|c|c|}
\hline & \multicolumn{3}{|c|}{ All participants } & \multicolumn{3}{|c|}{ Intervention group I } & \multicolumn{4}{|c|}{ Intervention group II } \\
\hline & $\mathbf{n}$ & Mean (SD) & $\left(\operatorname{Md}\left(Q_{1} ; Q_{2}\right)\right.$ & $\mathbf{n}$ & Mean (SD) & $\left(\operatorname{Md}\left(Q_{1} ; Q_{2}\right)\right.$ & $\mathrm{n}$ & Mean (SD) & $\left(\operatorname{Md}\left(Q_{1} ; Q_{2}\right)\right.$ & p-value \\
\hline \multicolumn{11}{|l|}{ FAFHES, T1 } \\
\hline Family function & 60 & $4,5(0,7)$ & $4,5(3,9 ; 5,1)$ & 32 & $4,5(0,7)$ & $4,3(3,9 ; 5,1)$ & 28 & $4,6(0,8)$ & $4,8(3,9 ; 5,1)$ & 0,472 \\
\hline Family health & 60 & $4,1(0,6)$ & $4,0(3,7 ; 4,5)$ & 32 & $3,9(0,5)$ & $3,8(3,6 ; 4,4)$ & 28 & $4,2(0,6)$ & $4,2(3,8 ; 4,7)$ & 0,041 \\
\hline Family support & 60 & $4,0(0,9)$ & $4,1(3,6 ; 4,7)$ & 32 & $4,0(0,8)$ & $4,0(3,5 ; 4,7)$ & 28 & $4,0(1,0)$ & $4,3(3,6 ; 4,8)$ & 0,386 \\
\hline \multicolumn{11}{|l|}{ FAFHES, T2 } \\
\hline Family function & 52 & $4,5(0,8)$ & $4,5(3,8 ; 5,1)$ & 30 & $4,4(0,8)$ & $4,4(3,8 ; 5,0)$ & 22 & $4,6(0,8)$ & $4,7(4,0 ; 5,3)$ & 0,304 \\
\hline Family health & 52 & $4,2(0,6)$ & $4,1(3,8 ; 4,4)$ & 30 & $4,1(0,6)$ & $4,0(3,6 ; 4,5)$ & 22 & $4,3(0,7)$ & $4,3(3,8 ; 4,8)$ & 0,247 \\
\hline Family support & 52 & $4,9(0,7)$ & $4,9(4,4 ; 5,5)$ & 30 & $5,2(0,6)$ & $5,1(4,8 ; 5,6)$ & 22 & $4,5(0,8)$ & $4,5(3,8 ; 5,0)$ & 0,001 \\
\hline \multicolumn{11}{|l|}{ FAFHES, T3 } \\
\hline Family function & 42 & $4,5(0,8)$ & $4,6(3,9 ; 5,1)$ & 20 & $4,4(0,8)$ & $4,6(3,9 ; 4,9)$ & 22 & $4,6(0,9)$ & $4,7(4,0 ; 5,3)$ & 0,399 \\
\hline Family health & 42 & $4,2(0,6)$ & $4,3(3,7 ; 4,6)$ & 20 & $4,0(0,6)$ & $4,1(3,5 ; 4,4)$ & 22 & $4,4(0,6)$ & $4,5(4,2 ; 4,8)$ & 0,054 \\
\hline Family support & 42 & $5,0(0,7)$ & $5,0(4,6 ; 5,5)$ & 20 & $4,9(0,7)$ & $5,0(4,5 ; 5,4)$ & 22 & $5,1(0,7)$ & $5,2(4,7 ; 5,6)$ & 0,204 \\
\hline
\end{tabular}

\section{The effects regarding the onset of DFG intervention}

Families, who were delivered the DFG intervention at once (Intervention group I) experienced increasing family health $(p=0,001)$ and increasing family support $(p<0,001)$ after the DFG (T2). Furthermore, these families experienced more social support still three months after the DFG intervention had ended (T3) compared to baseline (T1) ( $<<0,001)$ (Table 4).

Intervention group II was delivered the DFG intervention three months from baseline (T1). These families experienced more social support three months after baseline (T2) compared to baseline $(T 1)(p=0,011)$, despite not having received the DFG intervention at that point. When making comparisons for Intervention group II after three months (T3) from the DFG intervention starting point to baseline (T1), statistically significant changes concerning the experience of Social support $(p<0,001)$ can be noticed (Table 4$)$.

Table 4. Comparison between Intervention group I and II based on the onset of the DFG intervention

\begin{tabular}{|c|c|c|c|c|c|c|c|c|c|c|c|c|}
\hline & \multicolumn{4}{|c|}{ All participants } & \multicolumn{4}{|c|}{ Intervention group I } & \multicolumn{4}{|c|}{ Interventio group II } \\
\hline & \multirow[b]{2}{*}{$\mathbf{n}$} & \multirow[b]{2}{*}{$\begin{array}{l}\text { Mean } \\
\text { (SD) }\end{array}$} & \multicolumn{2}{|l|}{ Cl $95 \%$} & \multicolumn{4}{|c|}{ Cl $95 \%$} & \multirow[b]{2}{*}{$\mathrm{n}$} & \multicolumn{3}{|c|}{ Cl $95 \%$} \\
\hline & & & $\begin{array}{l}\text { lower, } \\
\text { upper }\end{array}$ & $\begin{array}{l}\mathrm{p}- \\
\text { value }\end{array}$ & $\mathrm{n}$ & Mean (SD) & $\begin{array}{l}\text { lower, } \\
\text { upper }\end{array}$ & $\begin{array}{l}\text { p- } \\
\text { value }\end{array}$ & & $\begin{array}{l}\text { Mean } \\
\text { (SD) }\end{array}$ & $\begin{array}{l}\text { lower, } \\
\text { upper }\end{array}$ & $\mathbf{n}$ \\
\hline \multicolumn{13}{|l|}{ FAFHES, T2-T1 } \\
\hline $\begin{array}{l}\text { Family } \\
\text { function }\end{array}$ & 52 & $\begin{array}{l}-0,04 \\
(0,39)\end{array}$ & $-0,15 ; 0,07$ & 0,445 & 30 & $-0,05(0,36)$ & $-0,18 ; 0,09$ & 0,481 & 22 & $-0,03(0,43)$ & $-0,22 ; 0,16$ & 0,719 \\
\hline Family health & 52 & $\begin{array}{c}0,17 \\
(0,36)\end{array}$ & 0,$07 ; 0,27$ & 0,001 & 30 & $\begin{array}{r}0,25 \\
(0,34)\end{array}$ & 0,$12 ; 0,38$ & 0,001 & 22 & $0,06(0,35)$ & $-0,09 ; 0,22$ & 0,398 \\
\hline Family support & 52 & $\begin{array}{c}0,86 \\
(0,83)\end{array}$ & 0,$62 ; 1,09$ & $<0,001$ & 30 & $\begin{array}{c}1,07 \\
(0,70)\end{array}$ & 0,$82 ; 1,34$ & $<0,001$ & 22 & $0,55(0,92)$ & 0,$14 ; 0,96$ & 0,011 \\
\hline \multicolumn{13}{|l|}{ FAFHES, T3-T1 } \\
\hline $\begin{array}{l}\text { Family } \\
\text { function }\end{array}$ & 42 & $\begin{array}{l}-0,05 \\
(0,53)\end{array}$ & $-0,21 ; 0,12$ & 0,562 & 20 & $-0,05(0,70)$ & $-0,37 ; 0,28$ & 0,763 & 22 & $-0,05(0,33)$ & $-0,20 ; 0,10$ & 0,507 \\
\hline Family health & 42 & $\begin{array}{c}0,17 \\
(0,45)\end{array}$ & 0,$03 ; 0,31$ & 0,021 & 20 & $0,27(0,51)$ & $-0,07 ; 0,41$ & 0,151 & 22 & $0,17(0,41)$ & $-0,02 ; 0,35$ & 0,071 \\
\hline Family support & 42 & $\begin{array}{c}0,98 \\
(0,87)\end{array}$ & 0,$71 ; 1,26$ & $<0,001$ & 20 & $0,72(0,64)$ & 0,$41 ; 1,01$ & $<0,001$ & 22 & $1,24(0,99)$ & 0,$80 ; 1,67$ & $<0,001$ \\
\hline
\end{tabular}

At T2, the quality of the relationship between parents was also statistically significantly connected to family functionality and family health. Those families who had an excellent or good relationship between parents $\left(M d 4,6 ; Q_{1} 4,3 ; Q_{2} 5,2\right)$ had better family functionality $(0,001)$ than those who had a moderate, poor or very poor relationship between parents ( $M d 3,8 ; Q_{1} 3,6 ; Q_{2} 4,6$ ). Also, those families who had an excellent or good relationship between parents (Md 4,3; Loading [MathJax]/jax/output/CommonHTML/jax.js 009) than those who had a moderate, poor or very poor relationship between parents (Md 3,9; $\left.Q_{1} 3,6 ; Q_{2} 4,1\right)$. 


\section{Participants`assessment of DFG}

Parents completed DFG questionnaire during the last DFG session. Most parents taking part in this study felt that DFG was provided at an appropriate time for them, although some received it at once and some after waiting for a three monthsperiod. Parents opinion in Intervention group I and II concerning the onset for DFG intervention were immediately, or one month after the child visits the clinic for the first time. Six sessions is usual for DFG, and this was seen as adequate for most parents. Parentsfe < tâllthefamilymembersweretaken $\int$ oconsrationdur $\in$ gtheDFGsessions. Parents felt that they got advice and practical guidance, and that DFG helped them to manage better with their child having NDD. The parents taking part in this study also recommend DFG as suitable to be delivered to other families (Table 5). 


\begin{tabular}{|c|c|c|}
\hline & \multicolumn{2}{|c|}{ All participants } \\
\hline DFG-instrument & $\mathbf{n}$ & $\%$ \\
\hline \multicolumn{3}{|l|}{ Who gave the information about DFG } \\
\hline Doctor & 12 & 23,5 \\
\hline Nurse & 39 & 76,6 \\
\hline \multicolumn{3}{|l|}{ Was the DFG at appropriate time for your family } \\
\hline Yes & 49 & 96,1 \\
\hline No & 2 & 3,9 \\
\hline \multicolumn{3}{|l|}{ When is the right time for DFG } \\
\hline At once & 29 & 59,2 \\
\hline After 1 month & 16 & 32,7 \\
\hline After 2-4 months & 4 & 8,1 \\
\hline \multicolumn{3}{|l|}{ How many DFG-sessions did you have } \\
\hline $1-5$ & 2 & 4,0 \\
\hline 6 (ordinary for DFG) & 49 & 96,0 \\
\hline \multicolumn{3}{|l|}{ Is six DFG-sessions adequate } \\
\hline Yes & 44 & 86,3 \\
\hline No & 7 & 13,7 \\
\hline \multicolumn{3}{|l|}{ What is adequate number of DFG-sessions } \\
\hline $4-5$ & 2 & 4,0 \\
\hline 6 & 44 & 86,3 \\
\hline 7 or more & 5 & 9,8 \\
\hline \multicolumn{3}{|l|}{ Did you have DFG-sessions outside the clinic } \\
\hline Yes & 3 & 5,9 \\
\hline No (usual in DFG) & 48 & 94,1 \\
\hline \multicolumn{3}{|l|}{ Are DFG-sessions outside clinic needed } \\
\hline Yes & 18 & 36,0 \\
\hline No & 32 & 64,0 \\
\hline \multicolumn{3}{|l|}{ What is best time for one DFG-session } \\
\hline 45 minutes & 1 & 2,0 \\
\hline 60 minutes & 9 & 9,0 \\
\hline 90 minutes (ordinary for one DFG session) & 41 & 80,4 \\
\hline \multicolumn{3}{|l|}{ Who were delivering DFG-sessions for your family } \\
\hline Nurse & 45 & 88,2 \\
\hline Social worker & 6 & 11,8 \\
\hline \multicolumn{3}{|l|}{ Were all family members taken into consideration } \\
\hline Yes & 49 & 96,1 \\
\hline No & 2 & 3,9 \\
\hline \multicolumn{3}{|c|}{ Do you recommend DFG-sessions to other families } \\
\hline Yes, absolutely & 43 & 84,3 \\
\hline Yes & 8 & 15,7 \\
\hline \multicolumn{3}{|l|}{ Did you get practical advice and tips } \\
\hline nonHTML/jax.js ely & 30 & 58,8 \\
\hline
\end{tabular}




\begin{tabular}{|c|c|c|}
\hline Yes & 20 & 39,2 \\
\hline Maybe & 1 & 2,0 \\
\hline \multicolumn{3}{|c|}{ How much did DFG help you to manage with your child } \\
\hline Very much & 20 & 39,2 \\
\hline Much & 26 & 51,0 \\
\hline A little & 5 & 9,8 \\
\hline
\end{tabular}

\section{Responses to the open-ended question about DFG}

A semi-structured open-ended question was included in the DFG-questionnaire, asking: "Could you write about your experiences, comments or/and ideas about how to improve DFG?". The parents' answers were analysed, categories were created and grouped, and similar answers were combined to form five main categories.

The first main category "Practical guidance for daily life" included the subcategories "Experience of getting practical guidance" and "New procedure models for daily life".

The second main category "To be listened to" included the subcategories "Experience of getting tailored tips for daily life", "Good parent and family discussions during the DFG-sessions", and "Experience of professionals listening to parents".

The third main category "Getting information" included subcategories "Having the experience to understand their own child better" and "Experience of getting information as parents".

The fourth main category "Positive feedback about own parenthood" included the subcategories "Experience of getting positive feedback as parents" and "Getting strength to voice one`s own opinions".

The fifth main category "DFG was a needed and rewarding experience" included subcategories "DFG is a positive experience" and "DFG gave attention to every family member".

Improvement ideas presented by parents were eg that DFG would include more than six sessions and evening sessions would be appreciated. Parents` also hoped DFG-therapists to make home visits and offer them help with the implementation in their home environment.

\section{Discussion}

The aim of this research was to study the effects of the intervention Dialogical Family Guidance aimed for target group families, using the FAFHES and DFGquestionnaires. These randomised families were also compared between Intervention group I (onset immediately) and II (onset after three months) and surprisingly, there were no major differences between group I and II. The main finding in this study was that DFG improved family health and family support in both groups. All participants reported being satisfied with the help they received and especially family support increased by parents reports between baseline and after DFG.

Families in both intervention groups gained an increasing experience of family support. Nearly all families would recommend DFG to other families. Their experience was that they got practical guidance, they had good discussions and they were listened to during the DFG sessions. The first impression is, that DFG targets the needs of families with a child with NDD. This result is encouraging and DFG intervention seems to be feasible. Therefore, it is justified to continue delivering DFG intervention to families with a child with NDD as an additional type of support.

Surprisingly, families in this study group reported family functionality, family health and family support as moderate or good at every measure point. According to previous studies $[13,15,17]$, it was unexpected to get these relatively good values already from baseline. This can be associated to the fact that the children with NDD in these families' were university hospital ordinary treatment patients during this study. It can be assumed that families taking part of this study were at the same time getting ongoing care for their child and this could explain the proportional good baseline reports.

Although families expressed moderate or good values already at baseline, there were still some positive changes concerning the experience of family health and family support in both groups (Intervention group I and II) after DFG, compared to baseline. On the other hand, family functionality did not change as much as expected. According to a review made by Johnston and Mash [16] there are many factors in family environment, family relationship and family psychology/dynamics influencing these target families. Accordingly, it is difficult to find one specific reason to the minimal change concerning family functionality in this study and it can be assumed that several different factors are influencing. Yet, the quality of relationship between parents was connected to family functionality and family health. Those families with excellent or good parental relationships between parents, also had better family functionality and family health. This is in line with several studies[15-18,47] reporting that the nature of NDD symptoms reflect and influence the whole family, including marital problems. Naturally, stressful and demanding nature of NDD symptoms may elicit marital miscommunication and inconsistencies in parenting or low frustration tolerance between parents. Marital dysfunction was not studied in this study profoundly, but according to Hartley et al. (2010) the risk of divorce is significantly high in parents of children with autism and reminds us about the need to pay attention to the relationship of the parents during family interventions. 
Obviously, families in this study have children with different range of NDD disorders. Child

scharacteristicscanevoke $\neg$ ativereactionsbetweenfamilymembers, and rest $\in$ dyunctionalparent $\in$ gpractices. Craigetal[15]comparedthe.

s behavior, social and emotional problems may more easily increase levels of stress in parents and bring tension in the parent-child relationship [15-17].

Repetitive unsuccessful parental efforts to control child behavior can decrease parent self-esteem, emotional well-being and affect negatively on their parenting identity. Parents in this study expressed that positive feedback about their own parenthood was important and that DFG was rewarding experience as a parent. As caregivers are often included in different interventions, it seems to have a strengthening impact on parenthood identity when getting positive feedback concerning their parenthood and parental skills from professionals.

The background variables in both intervention groups show that daily life parenting was statistically significant connected to family functionality and family health. Parents

$\in$ thisstudyexperiencedttheyreceivedadvice and practicalgunce $\rightarrow$ helptheirdailyl if e. Thishelpedthem $\rightarrow$ mana $\geq$ beerwiththeir $\chi$ ldwithl knowledge and skills can reduce stress and offer parents empowerment. Having enough knowledge as parent, can foster a sense of independence and give confidence in managing something that they previously found difficult.

Based on several studies[6-9] there is due to high heritability rate increased prevalence of same kind of symptoms or even diagnosis in parents and siblings of children with NDD. In this study approximately one third of parents agreed that there were more than one family member with neurodevelopmental disorders. To the question concerning parents having long-term illness or neuropsychiatric disorder themselves, also several parents answered "yes". According to Rucklidge et al [22] men and women with ADHD, regardless of gender, are struggling significantly with their own psychosocial functioning. It can be assumed that also in this study, the dynamics between family members has negative effect, not only caused by the child with NDD, but also by genetic characteristics of the parent. As mentioned before, this can cause impairments in parental functioning according to Johnston \& Mash [16].

Apparently, that the role of parental attributions in children's responses to treatment is essential. When collaborating with families in this target group all family members need to be involved. In this study, nearly all the parents reported that all family members were taken into consideration, and a family systems perspective was put into practice, and this was significant to parents. Also, the study by Caicedo [13] claims that families need interventions to improve health and functioning for both parents and the children. Ansari et al [27] confirm that relationships among individuals within the family are known to have a unique influence on the overall family system, and that professionals can help parents in establishing positive thinking towards the child. Our evaluation about DFG effects conclude same kind of findings.

Parents reported in their DFG-questionnaire, that DFG should be delivered to families very quickly after the child`s first visit to the clinic. Nearly all parents in both groups experienced that the time they were delivered DFG intervention for their family was well-timed. This finding was unexpected, because it seems that three months waiting time for the onset of DFG did not cause much difference to parents. Maybe this is due to the fact, that families have already struggled several years with neuropsychiatric and psychiatric problems in their family and three months waiting for DFG, is not causing much difference. According to Moen, Hedelin \& Hall-Lord [20] social support and the support from the community health services are strongly positively associated to family functioning. The knowledge of upcoming DFG can probably provide families comfort and alleviate their feeling of stress to some degree. Families attending this study followed the study protocol and time schedule, and the selection of families did proceed randomly contrary to ordinary clinical work, where DFG is targeting primary families with an actual need for it.

It is well-known that the family environment is an important factor in the development of every child, and family dysfunction may serve as a risk factor that poses a bad influence for the child

sdevelo \pm ent and onpresentationsofNDDsymp $\rightarrow$ ms. Itseemstĉllab or ativeapproachwithparentsofferhelp $\rightarrow$ parents $\rightarrow$ nt if $y w a ̂ s p e c t:$

emotions, expectations and disappointments. With the help of dialogue, family members get a possibility to process and share their experiences combined with the psychoeducation and guidance in practical issues from the professionals. This study supports Evans et al[41] findings demonstrating parents need for space to discuss their worries and reflect thoughts and feelings. This needs to be considered as an important factor in family interventions.

In the future, DFG needs to be tested with families with children with NDD in this target group having already basic health care contact for their child. At present, there is need to have knowledge about DFG's effectivity in families having low family functionality and family health at baseline. Studies to gain more accurate information how DFG helps parents to develop a more positive relationship with their children, are needed. At this moment we do not know what effects DFG has on the child with NDD with various age range. Research performed with larger number of families within different levels and settings of healthcare will widen our understanding and knowledge concerning DFG. It would give us information whether this treatment can be used in other diagnostic or disease groups with long term and various difficult problems, eg families with mentally retarded children or other neuropediatric disorders.

\section{Study limitations}

The FAFHES questionnaire has been tested since 2002 [39] and ever since used in several clinical contexts, e.g. pediatric intensive care, and child maltreatment in families expecting a baby $[44,45]$. The questionnaire was modified for and tested in a pilot study and seemed to be applicable for families of children with NDD [33]. It needs to be noticed, that this modified FAFHES questionnaire has not yet been used in other studies.

Another limitation is the small sample size of families who completed all the phases (thirty-four families completed the whole protocol). The results should be followed by further research evaluating DFG with a larger sample size. However, it can be assumed that DFG has desired intervention effects, because all families reported being satisfied with the help they received. This gives some evidence that tailored DFG intervention can benefit families in this cohort group.

Loading [MathJax]/jax/output/CommonHTML/jax.js 
All families included were from the same neuropsychiatric outpatient clinic at the university hospital, and therefore the results do not include any comparison between other outpatient clinics or hospitals. Parents in this study are representative concerning the focus group, because they all have a child with at least one NDD diagnosis. The child started as university hospital ordinary treatment patient during this study and the families were at baseline measure involved in the child’s assessment and treatment plan. Families from several different clinics would offer wider knowledge about families having various baseline experiences.

Several studies reveal that families to children with NDD experience multiple challenges causing stress, burden, exhaustion and emotional problems. However, these study group families are untypical related to their own sample, because all these families surprisingly reported family functionality, family health and family support as moderate already at baseline. Hospital involvement can explain why the parents reported their families as well-functioning already at baseline. This is a limitation and needs to be taken into consideration when reading the results. These relatively good baseline values most likely affect also the three and six-months follow up values. This study is limited to give knowledge about DFG's effects only concerning families with relatively good baseline values for family functionality and family health.

The result of this study is limited concerning the effects of DFG and further research is required. A longer follow up is needed to receive knowledge about the long-term effects of DFG.

Although the children were taking part of the DFG sessions, they did not fill in their own questionnaires and the children sonnionsare $\neg$ partoftherest $\in$ thisstudy. Therests $\in$ thisstudy $\in$ volveonlytheparents opinions and the children `s voice is not appearing true themselves.

The professionals worked in pairs when delivering the intervention and a check-list manual was used. In this way the DFG interventions implemented to families was apparently homogeneous in quality and delivered in-line with laid out the DFG intervention structure. The professionals received their DFG education from the same educator. In this way, the DFG implementers got equally their training. The researcher was not involved in any way with the families and did not deliver DFG to families taking part of this study.

\section{Clinical implications}

It is important for families to get information in forward concerning accurate timing for upcoming family intervention. This already can affect positively families` experience of family support.

Varying degree disturbances in families with a child with NDD can affect health of all family members. Systems perspective and family interventions involving the entire family are needed.

Practical guidance and psychoeducation offered thru dialogue with family members allow families targeted support.

Knowledge presented in this study may be useful and should be noticed when planning family interventions and support for this target group families.

\section{Conclusion}

The study findings suggest that the DFG intervention may strengthen parent experiences of family support. Managing as a parent in daily life and the relationship between parents was associated with family functionality and family health. Responses from DFG parent questionnaire report that practical guidance, information, dialogue between staff and parents and positive feedback for own parenthood are strengthening factors. Parents felt that advice and practical guidance helped them better manage with their child with NDD. This study confirms earlier studies considering the knowledge and understanding about the target families' needs of support, although families in this study already at baseline had well-functioning families. It can be assumed that in addition to the information provided, it is important to offer parents opportunity to have a dialogue about their experiences and emotions they face in their daily life with the child. Delivering DFG as a family intervention implemented by healthcare staff may be recommended as an additional type of support for families with a child with NDD.

\section{Abbreviations}

DFG: Dialogical Family Guidance; ADHD: Attention Deficit Hyperactivity Disorder; ASD: Autism Spectrum Disorder; FAFHES: Family Functionality, Health and Social Support.

\section{Declarations}

\section{Ethics approval and consent to participate}

The ethical standards of the American Psychiatric Association and the Declaration of Helsinki were followed in this study [48]. The study has been granted ethics committee approval before the onset of the study $(2012,2013,2015)$ from Helsinki University Hospital ethical committee of psychiatry (nr:106/13/03/03/2012) and research approval from University Hospital board was received 2012, 2013 and 2015. This study is registered to ClinicalTrials.gov with an identifier: NCT04892992 on May 18, 2021 (retrospective registered). All the procedures performed in the study are in accordance with the ethical standards of the institutional research committee, and with the 1964 Helsinki Declaration and its later amendments. Informed consent to participate in this study was obtained both orally and in writing from all participants included in the study.

Loading [MathJax]/jax/output/CommonHTML/jax.js 


\section{Consent for Publication}

Not applicable.

\section{Availability of data and materials}

The datasets used and analyzed during the current study are available from the corresponding author on reasonable request.

\section{Competing interests}

The authors declare that they have no competing interests.

\section{Funding}

Helsinki University Hospital and Finnish Cultural Foundation have supported this study by contributing research fund. Reporting of the study was supported by the Nursing Research Center, Helsinki University Hospital.

\section{Authors`contributions}

DC: conception, data collection, analysis, revising the article, final approval of the manuscript

MR: conception, interpretation, analysis, revising the article, final approval of the manuscript

CG: conception, design, revising the article, final approval of the manuscript

EB: conception, design, revising the article, final approval of the manuscript

AL: conception, design, drafting, interpretation, revising the article, analysis, final approval of the manuscript

The authors read and approved the final manuscript.

\section{Acknowledgements}

Our warmest thanks go to the many families who participated in this study, and the personnel working at the Helsinki University Hospital. The leaders of the hospital, as well as the clinicians proceeding with the DFG intervention with the families made this study possible and helped to develop a family intervention model suitable for clinical use. Special thank you to PhD, MD Arja Voutilainen for her collaboration and support at the clinic. We also want to thank Professor Päivi Åstedt-Kurki and her copyright holders at Tampere University, who gave permission to modify and use the FAFHES questionnaire for the studies concerning families with a child with NDD.

\section{Author details}

${ }^{1}$ Faculty of Social Science, Nursing Science

University of Tampere, Tampere, Finland

${ }^{2}$ Helsinki University Hospital (HUH)

Child psychiatry, Neuropsychiatric Unit, Helsinki, Finland

${ }^{3}$ Gillberg Neuropsychiatry Centre

Institute of Neuroscience and Physiology

University of Gothenburg, Sahlgrenska Academy, Gothenburg, Sweden

\section{${ }^{*}$ Corresponding author}

Diana Cavonius-Rintahaka

${ }^{1}$ Faculty of Social Science, Nursing Science

University of Tampere, Tampere, Finland

diana.cavonius@gmail.com

+358 405551511

${ }^{2}$ Helsinki University Hospital (HUH) 


\section{References}

1. Morris-Rosendahl, D.J. and M.A. Crocq, Neurodevelopmental disorders-the history and future of a diagnostic concept $₫$ Dialogues Clin Neurosci, 2020. 22(1): p. 65-72.

2. Willcutt, E.G., et al., Psychiatric comorbidity associated with DSM-IV ADHD in a nonreferred sample of twins. J Am Acad Child Adolesc Psychiatry, 1999. 38(11): p. 1355-62.

3. Gillberg, C., The ESSENCE in child psychiatry: Early Symptomatic Syndromes Eliciting Neurodevelopmental Clinical Examinations. Research in Developmental Disabilities, 2010. 31(6): p. 1543-1551.

4. Biederman, J., Introduction: new developments in the treatment of attention-deficit/hyperactivity disorder. J Clin Psychiatry, 2006. 67 Suppl 8: p. 4-6.

5. Thapar, A., et al., Does the definition of ADHD affect heritability? J Am Acad Child Adolesc Psychiatry, 2000. 39(12): p. $1528-36$.

6. Biederman, J. and S.V. Faraone, Attention-deficit hyperactivity disorder. Lancet, 2005. 366(9481): p. 237-48.

7. Hudziak, J.J., et al., The Genetic and Environmental Contributions to Attention Deficit Hyperactivity Disorder as Measured by the Conners' Rating ScalesRevised. American Journal of Psychiatry, 2005. 162(9): p. 1614-1620.

8. Chen, Q., et al., Familial aggregation of attention-deficit/hyperactivity disorder. J Child Psychol Psychiatry, 2017. 58(3): p. $231-239$.

9. Tick, B., et al., Heritability of autism spectrum disorders: a meta-analysis of twin studies. J Child Psychol Psychiatry, 2016. 57(5): p. 585-95.

10. Tick, B., et al., Autism Spectrum Disorders and Other Mental Health Problems: Exploring Etiological Overlaps and Phenotypic Causal Associations. J Am Acad Child Adolesc Psychiatry, 2016. 55(2): p. 106-13.e4.

11. Robert, C., et al., Role of Genetics in the Etiology of Autistic Spectrum Disorder: Towards a Hierarchical Diagnostic Strategy. Int J Mol Sci, 2017. 18(3).

12. Rommelse, N.N., et al., Shared heritability of attention-deficit/hyperactivity disorder and autism spectrum disorder. Eur Child Adolesc Psychiatry, 2010. 19(3): p. 281-95.

13. Caicedo, C., Families with special needs children: family health, functioning, and care burden. J Am Psychiatr Nurses Assoc, 2014. 20(6): p. 398-407.

14. Factor, R.S., et al., All in the Family: A Systematic Review of the Effect of Caregiver-Administered Autism Spectrum Disorder Interventions on Family Functioning and Relationships. Clin Child Fam Psychol Rev, 2019. 22(4): p. 433-457.

15. Craig, F., et al., Parenting stress among parents of children with Neurodevelopmental Disorders. Psychiatry Res, 2016. 242: p. 121-129.

16. Johnston, C. and E.J. Mash, Families of children with attention-deficit/hyperactivity disorder: review and recommendations for future research. Clin Child Fam Psychol Rev, 2001. 4(3): p. 183-207.

17. Duarte, C.S., et al., Factors associated with stress in mothers of children with autism. Autism, 2005. 9(4): p. 416-27.

18. Hartley, S.L., et al., The relative risk and timing of divorce in families of children with an autism spectrum disorder. J Fam Psychol, $2010.24(4)$ : p. 449-57.

19. Pisula, E. and A. Porebowicz-Dorsmann, Family functioning, parenting stress and quality of life in mothers and fathers of Polish children with high functioning autism or Asperger syndrome. PLoS One, 2017. 12(10): p. e0186536.

20. Moen $\emptyset$, L., B. Hedelin, and M.L. Hall-Lord, Parental perception of family functioning in everyday life with a child with ADHD. Scand J Public Health, 2015. 43(1): p. 10-7.

21. Arnold, E.H., S.G. O'Leary, and G.H. Edwards, Father involvement and self-reported parenting of children with attention deficit-hyperactivity disorder. J Consult Clin Psychol, 1997. 65(2): p. 337-342.

22. Rucklidge, J., et al., Attributional styles and psychosocial functioning of adults with ADHD: practice issues and gender differences. J Atten Disord, 2007. 10(3): p. 288-98.

23. Barlow, J., et al., Group-based parent training programmes for improving parental psychosocial health. Cochrane Database Syst Rev, 2014(5): $p$. Cd002020.

24. Dretzke, J., et al., The clinical effectiveness of different parenting programmes for children with conduct problems: a systematic review of randomised controlled trials. Child Adolesc Psychiatry Ment Health, 2009. 3(1): p. 7.

25. Michelson, D., et al., Do evidence-based interventions work when tested in the "real world?" A systematic review and meta-analysis of parent management training for the treatment of child disruptive behavior. Clinical child and family psychology review, 2013. 16(1): p. 18-34.

26. Lai, M.C., M.V. Lombardo, and S. Baron-Cohen, Autism. Lancet, 2014. 383(9920): p. 896-910.

27. Ansari, N.J., et al., Study of Parental Perceptions on Health \& Social Needs of Children with Neuro-Developmental Disability and It's Impact on the Family. J Clin Diagn Res, 2016. 10(12): p. Sc16-sc20.

28. Cavonius-Rintahaka, D., et al., Dialogical Family Guidance (dfg)-Development and implementation of an intervention for families with a child with neurodevelopmental disorders. Nursing Open, 2020. n/a(n/a).

29. Barlow, J. and S. Stewart-Brown, Behavior problems and group-based parent education programs. Journal Of Developmental And Behavioral Pediatrics: JDBP, 2000. 21(5): p. 356-370.

30. Peasgood, T., et al., The impact of ADHD on the health and well-being of ADHD children and their siblings. Eur Child Adolesc Psychiatry, 2016. 25(11): $p$. 1217-1231.

31. Trillingsgaard, T., A. Trillingsgaard, and C. Webster-Stratton, Assessing the effectiveness of the 'Incredible Years((R)) parent training' to parents of young children with ADHD symptoms - a preliminary report. Scand J Psychol, 2014. 55(6): p. 538-45.

32. Fosco, W.D., et al., Parent and child neurocognitive functioning predict response to behavioral parent training for youth with ADHD. Atten Defic Hyperact nicord 2018

Loading [MathJax]/jax/output/CommonHTML/jax.js

Page $14 / 15$ 
33. Cavonius-Rintahaka, D., et al., Health, functionality, and social support in families with a child with a neurodevelopmental disorder - a pilot study. Neuropsychiatr Dis Treat, 2019. 15: p. 1151-1161.

34. Kane, G.A., V.A. Wood, and J. Barlow, Parenting programmes: a systematic review and synthesis of qualitative research. Child Care Health Dev, 2007. 33(6): p. 784-93.

35. Bearss, K., et al., Effect of parent training vs parent education on behavioral problems in children with autism spectrum disorder: a randomized clinical trial. Jama, 2015. 313(15): p. 1524-33.

36. Barlow, J., et al., Group-based parent training programmes for improving emotional and behavioural adjustment in young children. Cochrane Database Syst Rev, 2016(8): p. Cd003680.

37. Farmer, J. and A. Reupert, Understanding autism and understanding my child with autism: an evaluation of a group parent education program in rural Australia. Aust J Rural Health, 2013. 21(1): p. 20-7.

38. Astedt-Kurki, P., et al., Development and testing of a family nursing scale. Western Journal Of Nursing Research, 2002. 24(5): p. 567-579.

39. Astedt-Kurki, P., et al., Further testing of a family nursing instrument (FAFHES). Int J Nurs Stud, 2009. 46(3): p. 350-9.

40. Seikkula, J. and D. Trimble, Healing elements of therapeutic conversation: dialogue as an embodiment of love. Fam Process, 2005. 44(4): p. 461-75.

41. Evans, G., et al., Parenting interventions in tic disorders: an exploration of parents' perspectives. Child Care Health Dev, 2015. 41(3): p. 384-96.

42. Astedt-Kurki, P., et al., Determinants of perceived health in families of patients with heart disease. J Adv Nurs, 2004. 48(2): p. 115-23.

43. Lepisto, S., et al., The family health, functioning, social support and child maltreatment risk of families expecting a baby. J Clin Nurs, 2017. 26(15-16): p. 2439-2451.

44. Hakio, N., et al., Parents' experiences of family functioning, health and social support provided by nurses-a pilot study in paediatric intensive care. Intensive Crit Care Nurs, 2015. 31(1): p. 29-37.

45. Lepistö, S., et al., The family health, functioning, social support and child maltreatment risk of families expecting a baby. J Clin Nurs, 2017. 26(15-16): p. 2439-2451.

46. Graneheim, U.H., B.M. Lindgren, and B. Lundman, Methodological challenges in qualitative content analysis: A discussion paper. Nurse Educ Today, 2017. 56: p. 29-34.

47. Hartley, S.L. and H.M. Schultz, Support needs of fathers and mothers of children and adolescents with autism spectrum disorder. J Autism Dev Disord, 2015. 45(6): p. 1636-48.

48. World Medical Association Declaration of Helsinki: ethical principles for medical research involving human subjects. Jama, 2013. 310(20): p. 2191-4.

\section{Figures}

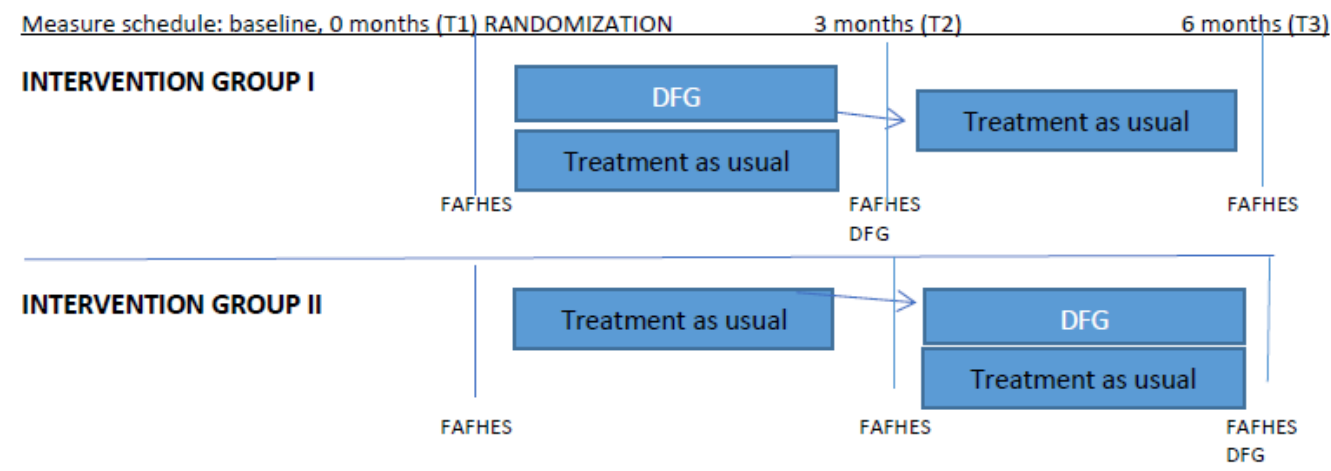

Figure 1

Study Design and data collection

\section{Supplementary Files}

This is a list of supplementary files associated with this preprint. Click to download.

- CONSORTExtensionforAbstractsChecklist.doc 